\title{
The use of magnesium sulphate for the treatment of severe pre-eclampsia and eclampsia
}

\author{
Page $\mid 76 \quad$ Jamilu Tukur \\ Department of Obstetrics and Gynaecology, Aminu Kano Teaching Hospital/ Bayero University, Kano, Nigeria
}

Correspondenceto: Dr J amilu Tukur, Department of O bstetrics and Gynaecology, Bayero University, Kano, Nigeria. E-mail: jtukur@yahoo.com

\begin{abstract}
Background: Pre-eclampsia and eclampsia are important causes of maternal and perinatal morbidity and mortality in the developing countries. There is need to provide the most effective management to pre-eclamptic and eclamptic patients. There is now evidence that magnesium sulphate is the most effective anticonvulsant.

Method: In this article, a literature review was made on the contribution of pre-eclampsia and eclampsia to maternal mortality and how it can be curtailed by the use of magnesium sulphate.

Results: The drug is administered by the Pritchard or Zuspan regimen, although modifications in the two protocols have been reported.

Conclusion: A Nigerian national protocol has been developed on its use. There is need for further training of health workers on how to use this important drug.
\end{abstract}

Keywords: Eclampsia; maternal mortality; magnesium sulphate; training

\section{Résumé}

Contexte: Pre-eclampsia et éclampsie sont importantes causes de morbidité maternelle et périnatale et mortalité dans les pays en développement. II est nécessaire de fournir le plus une gestion efficace de patients pre-eclamptic et eclamptic. Il y a maintenant preuve que le sulfate de magnésium est le plus efficace Antiépileptique.

Method: en Cet article une revue documentaire a été effectuée sur la contribution de traiter les prééclampsies et éclampsie à la mortalité maternelle et comment il peut être ralenti par l'utilisation de sulfate de magnésium.

Résultats: le médicament est administré par le schéma thérapeutique Pritchard ou Zuspan bien que les modifications apportées à les deux protocoles ont été signalés.

Conclusion: Un protocole national nigérian a été développé sur son utilisation. Il y a besoin de davantage de formation des travailleurs de santé sur l'utilisation de cette drogue importante.

Mots cles: Éclampsie; la mortalité maternelle, sulfate de magnésium; formation

PMID: 19805935

\section{Introduction}

Eclampsia is a common cause of maternal mortality worldwide but particularly in the developing countries. It is estimated that every year eclampsia is associated with about 50,000 maternal deaths worldwide, most of which occur in developing countries. ${ }^{[1]}$ Nigeria has one of the highest rates of maternal mortality in the world. Eclampsia has been noted to be among the most common causes of maternal mortality in Nigeria. The review of maternal deaths in Kano state for example showed that eclampsia was the most common cause of the deaths and contributed $46.3 \%$ of all the deaths in one study ${ }^{[2]}$ and $31.3 \%$ in another. ${ }^{[3]}$ In Birnin Kudu, eclampsia contributed $43.1 \%$ of all maternal deaths, ${ }^{[4]}$ 
while in Yenagoa and Ilorin, the contribution was $40 \%{ }^{[5]}$ and $27.5 \%,{ }^{[6]}$ respectively. It could indeed be argued that these are merely hospital statistics which do not reflect what is really happening in the community. However in an environment where registration of birth and death are not compulsory, these figures are often all that is available to give an indication of the real picture. What is quite clear is that eclampsia is a major killer of pregnant women in our environment and all efforts aimed at reducing its menace are welcome.

In the developing countries, there is low utilization of both antenatal and intrapartum care and the patients may present to the hospital only as a last resort. The opportunity to detect women at the preeclamptic phase is therefore usually lost. In addition, the World Health Organization (WHO) estimates that only $40 \%$ of births in developing countries take place in health facilities. ${ }^{[7]}$ When delivery care is sought, it is done late, after a lot of delays and this contributes to maternal mortality. Yet, prenatal care and supervision of delivery by trained birth attendants are said to be the best and cost-effective means of reducing maternal and perinatal mortality and morbidity. ${ }^{[8,9]}$

\section{The Magpie Trial}

Magnesium sulphate $\left(\mathrm{MgSO}_{4}\right)$ was first introduced to control convulsions in 1925, but it was the Collaborative Eclampsia Trial in 1995 that confirmed the efficacy of $\mathrm{MgSO}_{4}$ in the treatment of severe preeclampsia and eclampsia. The trial (also called Magpie trial) was a randomized, placebocontrolled study that enrolled over 10,000 women in 33 countries and across a wide variety of clinical settings. Four centers in Nigeria---Ibadan, Sagamu, Port Harcourt and Sokoto---participated in the study. ${ }^{[10]}$ Women treated with $\mathrm{MgSO}_{4}$ had a $52 \%$ and $67 \%$ lower recurrence of convulsions than those treated with diazepam and phenytoin, respectively. ${ }^{[1]}$ Use of $\mathrm{MgSO}_{4}$ in patients with severe pre-eclampsia reduced the risk of progression to eclampsia by more than half and reduced maternal mortality. [12] The effect of $\mathrm{MgSO}_{4}$ on perinatal outcomes was also studied, demonstrating significantly improved outcomes for newborns compared to phenytoin. ${ }^{[13]}$ Recently, the 2-year outcome following the use of $\mathrm{MgSO}_{4}$ in the Magpie trial was published. The reduction in the risk of eclampsia following prophylaxis with $\mathrm{MgSO}_{4}$ was not associated with an excess of death or disability for the women after 2 years in the group that had $\mathrm{MgSO}_{4}$ compared to placebo. ${ }^{[14]}$ The children whose mothers were treated with $\mathrm{MgSO}_{4}$ were also studied at the age of 18 months. The use of the $\mathrm{MgSO}_{4}$ was not associated with a difference in the risk of death or disability for the children at 18 months of age compared to those whose mothers were treated with placebo. ${ }^{[15]}$

\section{Mechanism of Action}

The mechanism of action of $\mathrm{MgSO}_{4}$ is not completely understood. It is thought to cause dilatation of cerebral blood vessels thus reducing cerebral ischemia. It is also thought that the magnesium blocks calcium receptors by inhibiting $\mathrm{N}$-methyl-Daspartate receptors in the brain. ${ }^{[16]}$ Magnesium also produces a peripheral (predominantly arteriolar) vasodilatation $^{[17]}$ thus reducing the blood pressure. It also acts competitively in blocking the entry of calcium into synaptic endings thus altering neuromuscular transmission. This transmission is affected by a preponderant presynaptic as well as a post-synaptic effect. The presynaptic release of acetylcholine is also reduced thus altering neuromuscular transmission. ${ }^{[18]}$ The precise mechanism of action for the tocolytic effects of $\mathrm{MgSO}_{4}$ is not clearly defined but may be related to the action of magnesium as a calcium blocker thus inhibiting muscle contractions. ${ }^{[19]}$

\section{Availability of $\mathrm{MgSO}_{4}$}

On the basis of the available evidence, The World Health Organization (WHO) has recommended $\mathrm{MgSO}_{4}$ as the most effective, safe, and low-cost drug for the treatment of severe pre-eclampsia and eclampsia. ${ }^{[20]}$ There are indeed several reports of its successful introduction in several countries including Nigeria and its effectiveness and safety for mother and baby. ${ }^{[21-24]}$

However, the drug has remained largely unavailable in several developing countries where it is incidentally needed the most. Leading advocates, researchers, non-governmental organizations, representatives of the $\mathrm{WHO}$ and national health ministries from all over the world recently met and identified the main barriers to the use and availability of $\mathrm{MgSO}_{4}$. These included the lack of guidelines on its use, non-inclusion in many national essential drug lists, the wrong perception that the drug is meant for use only at the highest level of facilities (such as those with intensive care facilities), lack of training of health workers on its use, little incentive for pharmaceutical companies to commercialize the drug, and ready availability of prepackaged forms of less effective drugs. ${ }^{[25]}$

In Nigeria, $\mathrm{MgSO}_{4}$ had remained a drug one read about but hardly saw. It was initially been produced by the drug-manufacturing unit of the University 
College Hospital, Ibadan, but this was not enough for the country. However, in the last 1 year, a pharmaceutical company has started importing the drug at an affordable rate. The drug is currently available in a number of centers and will hopefully replace the commonly available diazepam in this country in the near future. With the availability of the drug comes the need for training and retraining on the use of this important drug.

Page $\mid 78$

$\mathrm{MgSO}_{4}$ Regimens

There are principally two main regimens available for the administration of $\mathrm{MgSO}_{4}$. In the Pritchard Regimen, the loading bolus dose of $4 \mathrm{~g}$ of $\mathrm{MgSO}_{4}$ is given slowly intravenously over $5-10 \mathrm{~min}$ and this is followed by $10 \mathrm{~g}$ given intramuscularly $(5 \mathrm{~g}$ in each buttock). Subsequently, $5 \mathrm{~g}$ is given intramuscularly into alternate buttocks every 4 h. ${ }^{[26]}$ In the Zuspan regimen, the loading dose consists of an initial intravenous dose of $4 \mathrm{~g}$ slowly over 5-10 $\mathrm{min}$ followed by a maintenance dose of 1-2 $\mathrm{g}$ every hour given by an infusion pump. ${ }^{[27]} \mathrm{A}$ gravity fed infusion set can be used in the absence of the pump especially in the developing countries. It should be noted that for the $50 \% \mathrm{MgSO}_{4}, 1 \mathrm{ml}$ of the solution contains $0.5 \mathrm{~g}$ of $\mathrm{MgSO}_{4}$, while for the $20 \%$ solution, $1 \mathrm{ml}$ contains $0.2 \mathrm{~g}$ of $\mathrm{MgSO}_{4}$. Monitoring is important to ensure that the right doses are administered and this is not an easy task. Whatever regimen chosen, the drug should be administered till $24 \mathrm{~h}$ after delivery or after the last fit (whichever comes last).

The choice of which regimen to use depends on a number of factors such as availability of staff to monitor the drug as well as the expertise of the staff. In resource-constrained settings, the Pritchard regimen may be easier to administer since it is given intramuscularly (could thus be administered by lower cadre of health workers). It, however, has the disadvantage of being very painful, a situation which is not desired for a patient on whom efforts are been made to lower the blood pressure. To counteract this, the intramuscular dose could be administered with about $2 \mathrm{ml}$ of $1 \%$ xylocaine in the same syringe.

Some workers have reported modifications in the above-mentioned regimens. $\mathrm{MgSO}_{4}$ has been used with the dose reduced to a loading dose of $4.5 \mathrm{~g}$ intravenously and maintained on intramuscular $1.5 \mathrm{~g}$ every $4 \mathrm{~h}$ until $12 \mathrm{~h}$ after delivery or the last fit. ${ }^{[28]}$ In another study, the loading dose was $10 \mathrm{~g}$ intramuscularly followed by a maintenance dose of $2.5 \mathrm{~g}$ intramuscularly every $4 \mathrm{~h}$ for $24 \mathrm{~h} .{ }^{[29]}$ The drug has been used as in Pritchard regime, but the duration of its administration reduced to $12 \mathrm{~h}$ after the initial loading dose. ${ }^{[30]}$ The fetomaternal outcome was similar to the two more famous regimens (Pritchard and Zuspan).

\section{Clinical Detection of Toxicity}

The main fear of toxicity was also laid to rest with the Magpie trial. Toxicity of the drug was monitored using clinical parameters. The parameters that need to be monitored are the knee jerk (should be present), respiratory rate (should be more than $16 /$ minute), and urine output (should be more than $25 \mathrm{ml} / \mathrm{min}$ ). These clinical parameters have been compared with serum levels of $\mathrm{MgSO}_{4}$. The first warning sign of toxicity is loss of the knee jerk which occurs at serum magnesium level of $3.5-5 \mathrm{mmol} / \mathrm{l}$. Respiratory paralysis occurs at 5-6.5 $\mathrm{mmol} /$, cardiac conduction is altered at more than $7.5 \mathrm{mmol} /$ while cardiac arrest occurs when serum magnesium exceeds $12.5 \mathrm{mmol} / \mathrm{l}^{[10,31]}$ However, with the above-mentioned protocols, the expected serum range of magnesium is $2-3.5 \mathrm{mmol} / \mathrm{l}^{10}$. Using the Pritchard regimen, a mean serum magnesium level of $2.1 \mathrm{mmol} / \mathrm{l}$ was found. ${ }^{[32]}$ Should toxicity be detected, however, the antidote is $1 \mathrm{~g}$ of $10 \%$ calcium gluconate given intravenously slowly over 10 minutes.

\section{Training on $\mathrm{MgSO}_{4}$}

The need has now emerged for refresher trainings for health workers in the use of $\mathrm{MgSO}_{4}$. Clinical protocols are particularly useful in guiding such workers. The Federal Ministry of Health has developed a national clinical service protocol for obstetric care. The protocol outlines the management of eclampsia and how $\mathrm{MgSO}_{4}$ can be used and monitored. ${ }^{[33]}$ There is need to distribute this protocol and train health workers all over the country on its use. It is also recommended that the protocol should be utilized nationally as a guideline thus ensuring universal dosage regimen that will also help in uniform studies and research.

Some workers have also reported the utilization of the protocol to suite the working environment in respect of the available facilities, staff, investigations, and even the regimen of $\mathrm{MgSO}_{4}$ used. In Kano state, for example, the protocol was institutionalized under the guidance of the state safe motherhood committee to incorporate the role played by nonphysicians in the care of patients with eclampsia including referral where necessary [Figure 1].

\section{Conclusion}

If all stakeholders are brought on board to ensure the availability and utilization of $\mathrm{MgSO}_{4}$ for the treatment of severe pre-eclampsia and eclampsia, 


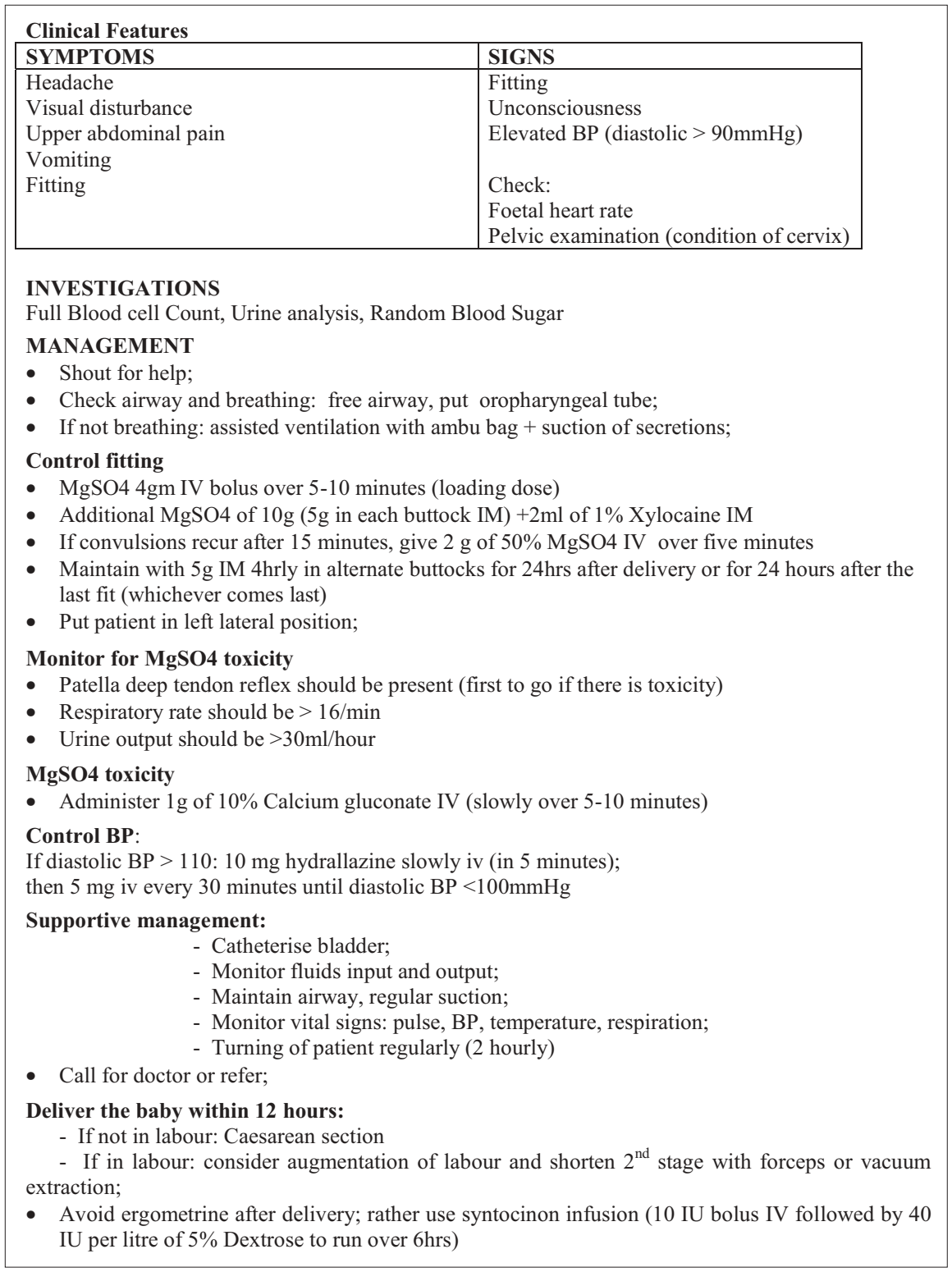

Figure 1: Kano State Eclampsia Protocol

their contribution to maternal mortality is likely to be reduced. These stakeholders include policy makers, trainers, health workers and even the patients and their relations.

\section{References}

1. Duley L. Maternal mortality associated with hypertensive disorders of pregnancy in Africa, Asia, Latin America and the Caribbean. Br J Obstet Gynaecol 1992;99:547-53.

2. Society of Gynaecology and Obstetrics of Nigeria (SOGON). Status of emergency obstetric service in six states of Nigeria: A needs assessment report. June 2004

3. Adamu YM, Salihu HM, Sathiakumar N, Alexander R. Maternal mortality in Northern Nigeria: A population based study. Eur J Obstet Gynaecol Rep Biol 2003;109:153-9.

4. Tukur J, Umar BA, Rabi'u A. Pattern of eclampsia in a tertiary health facility situated at a semi rural town in
Northern Nigeria. Ann Afr Med 2007;6:164-7.

5. Igbafe AA, Bariweni AC, Bennibor J, Gharoro EP. The Contribution of eclampsia to maternal mortality at the Federal Medical Center, Yenagoa. Trop J Obstet Gynaecol 2004;21:S9-10.

6. Aboyeji AP, ljaiya MA, Fawole AA. Maternal mortality in a Nigerian teaching hospital: A continuing tragedy. Trop J Obstet Gynaecol 2004;21:S8.

7. WHO. Coverage of maternity care. A list of available information. Geneva, Switzerland: Maternal and newborn health/Safe Motherhood. 1997

8. Harrison KA. Maternal mortality: A sharper focus on a major issue of our time. Trop J Obstet Gynecol 1988;1:913.

9. MCDonald TI, Coburn A. Predictors of prenatal care utilisation. Soc Sci Med 1988;27:167-72.

10. Ekele B. Magnesium sulphate: The gold standard for the treatment of eclampsia and severe pre-eclampsia. Trop J Obstet Gynaecol 2006;23:1-2.

11. The Eclampsia Trial Collaborative Group. Which anticonvulsant forwomen with eclampsia? Evidence from 
the collaborative eclampsia trial. Lancet 1995;345:145563.

12. Khan KS. Magnesium sulphate and other anticonvulsants for the treatment for severe preeclampsia. (Cochrane Review). In: The Reproductive Health Library, Issue 10, 2007. Oxford: Update Software Ltd.

13. Duley L, Henderson-Smart D. Magnesium sulphate versus phenytoin for eclampsia (Cochrane Review). In: The reproductive health library, Issue 10, 2007. Oxford: Update Software Ltd.

14. Magpie Trial Follow up Collaborative group. The magpie trial: A randomised trial comparing magnesium sulphate with placebo for preeclampsia: Outcome for women at 2 years. Br J Obstet Gynaecol 2007;114:300-9.

15. Magpie Trial Follow up Collaborative group. The Magpie Trial: A randomised trial comparing magnesium sulphate with placebo for preeclampsia: Outcome for children at 18 months. Br J Obstet Gynaecol 2007;114:289-99

16. Sadeh M. Action of Magnesium sulphate in the treatment of preeclampsia and eclampsia. Stroke 1989;20:1273-5.

17. Vigorito C, Giordano A, Ferraro P. Haemodynamic effects of magnesium sulfate on the normal human heart. Am J Cardiol 1990;65:709-12.

18. Krendel DA. Hypermagnesemia and neuromuscular transmission. Semin Neurol 1990;10:42-5.

19. Dube L, GranryJC. The therapeutic use of magnesium in anesthesiology, intensive care and emergency medicine: A review. Can J Anesth 1993;50:732-46.

20. World Health Organisation. Mother baby package: Implementing safe motherhood in countries. Geneva: WHO; 1994

21. Omu AE, Al Harmi J, Vedi HL, Mlechkova L, Sayed AF, Al-Ragum NS. Magnesium sulphate therapy in women with pre-eclampsia and eclampsia in Kuwait. Med Princ Pract 2008;17:227-32.

22. Adewole IF, Oladokun A, Okewole Al, Omigbodun AO, Afolabi A, Ekele B, et al. Magnesium sulphate for treatment of eclampsia: The Nigerian experience. Afr J Med Sci 2000;29:239-41.

23. Shamsudden L, Nahar K, Nasrin B, Nahar S, Tamanna S,
Kabir RM, et al. Use of parenteral magnesium sulphate in eclampsia and severe preeclampsia in a rural set up of Bangladesh. Bangladesh Med Res Counc Bull 2005;31:75-82.

24. Chaudary P. Eclampsia: Before and after magnesium sulphate. JNMA J Nepal Med Assoc 2005;44:124-8.

25. Langer A, Viller J, Tell K, Kim T, Kennedy S. Reducing eclampsia related deaths: A call to action. Lancet 2008; 371:705-6

26. Pritchard JA, Cunningham FG, Pritchard SA. The Parkland Memorial Hospital protocol for the treatment of eclampsia: Evaluation of 245 cases. Am J Obstet Gynaecol 1984;148:951-63.

27. Zuspan SP. Problems encountered in the treatment of pregnancy induced hypertension. Am J Obstet Gynaecol 1978;131:591-7.

28. Abdul MA, Ibrahim UN, Tukur J, Yusuf MD. Low dose Magnesium sulphate in the management of eclamptic fits: Randomised controlled trial. Trop J Obstet Gynaecol 2007:24:S21.

29. Begum R, Begum A, Johanson R, Ali MN, Akhter S. A low dose ("Dhaka") magnesium sulphate regime for eclampsia. Acta Obstet Gynecol Scand 2001;80:9981002.

30. Ekele BA, Ahmed Y. Magnesium sulphate regimens for eclampsia. Int J Gynaecol Obstet 2004;87:149-50.

31. Lu JF, Nightingale $\mathrm{CH}$. Magnesium sulphate in eclampsia and preeclampsia: pharmacokinetic properties. Clin Pharmacokinet 2000;38:305-14.

32. Ekele BA, Badung SL. Is serum magnesium estimate necessary for patients with eclampsia on magnesium sulphate? Afr J Reprod Health 2005;9:128-32.

33. Federal Ministry of Health. National Clinical service protocol for obstetric care. Federal Ministry of Health Abuja; 2005. p. 234-8.

Source of Support: Nil, Conflict of Interest: None declared.

\section{Author Help: Online submission of the manuscripts}

Articles can be submitted online from http://www.journalonweb.com. For online submission, the articles should be prepared in tw o files (first page file and article file). Images should be submitted separately.

1) First Page File:

Prepare the title page, covering letter, acknowledgement etc. using a word processor program. All information related to your identity should be included here. Use text/rtf/doc/pdf files. Do not zip the files.

2) Article File:

The main text of the article, beginning with the Abstract to References (including tables) should be in this file. Do not include any information (such as acknowledgement, your names in page headers etc.) in this file. Use text/ rtf/doc/pdf files. Do not zip the files. Limit the file size to $400 \mathrm{~kb}$. Do not incorporate images in the file. If file size is large, graphs can be submitted separately as images, without their being incorporated in the article file. This will reduce the size of the file.

3) Images:

Submit good quality color images. Each image should be less than 2048 kb (2 M B) in size. The size of the image can be reduced by decreasing the actual height and width of the images (keep up to about 6 inches and up to about $1800 \times 1200$ pixels). J PEG is the most suitable file format. The image quality should be good enough to judge the scientific value of the image. For the purpose of printing, always retain a good quality, high resolution image. This high resolution image should be sent to the editorial office at the time of sending a revised article.

4) Legends:

Legends for the figures/images should be included at the end of the article file. 